\title{
Sobre mestiçagem étnica \\ e expressão da arte
}

\author{
Neusa Romero Barazal*
}

\section{RESUMO}

Considerando que a história da humanidade é a história dos movimentos migratórios e suas consequentes miscigenações, esta reflexão pretende estabelecer uma aproximação entre a mestiçagem étnica, a arte e a religião. Devido à universalidade da arte e da religião como elementos culturais presentes em todas as sociedades, a mestiçagem aqui será entendida como processo de encontro entre as particularidades culturais que resultam em novas formas misturadas de expressar a arte e a religião mestiças na América Latina.

Palavras-chave: cultura, mestiçagem, artes, religião.

\section{ABOUT ETHNIC MISCEGENATION AND ART EXPRESSION}

\begin{abstract}
Bearing in mind that the history of humanity is the history of migratory movements and consequent miscegenation, this article intends to establish a link between ethnic miscegenation, art and religion. Because of the universality of art and religion as cultural elements present in all societies, miscegenation is understood here as a process of encounter between the cultural particularities that result in new forms of expressing mestizo art and religion in Latin America.
\end{abstract}

Keywords: Culture, Miscegenation, Arts, Religion.

Ao observar a história da civilização humana percebe-se que todas as culturas nela existentes representam respostas formalizadas às exigências da vida de cada uma delas e, portanto, com seus próprios

* Doutora em Ciências Sociais - Relações Internacionais: PUC - Pontifícia Universidade de São Paulo. Mestre em Integração da América Latina: USP - PROLAM - Programa Integração América Latina. Professora Universitária: Centro Universitário Fundação Santo André. 
conteúdos. Esses conteúdos são constantemente adaptados e têm correlação direta com o espaço (habitat) e o tempo (contexto) vividos pela respectiva população. No entanto, apesar das suas particularidades próprias, há elementos universais que se repetem em cada uma delas como, por exemplo, a língua, a tecnologia, a mitologia, o sistema social, a propriedade, o governo, a guerra, a arte e a prática religiosa. A essa universalidade de certos aspectos da cultura se conectam as necessidades psíquicas e biológicas que são básicas no ser humano, independentemente do tempo e do espaço considerado.

Desse modo, pode-se iniciar dizendo que o surgimento das culturas e etnias resulta da necessidade e do interesse de adaptação e sobrevivência dos indivíduos e "o fato de variarem tão amplamente de uma para outra sociedade significa apenas que são as múltiplas soluções contrárias procedentes de uma base universal que caracterizam a cultura humana" (HERSKOVITS, 1973, P.19).

Desde as Descobertas existem escritos sobre a experiência vivida pelos europeus e pelos povos descobertos, ressaltando seus aspectos positivos e negativos, referindo-se à miscigenação racial e cultural decorrente desses encontros. Tal tema ressurge sob novas perspectivas e novos enfoques visando melhor compreender o fenômeno da mestiçagem que tem representado um grande desafio para a humanidade e para o homem globalizado. Ao haver um "estreitamento" do mundo, devido às proximidades provocadas pela tecnociência informática, ocorre também uma intensificação de encontros entre diferentes sociedades e culturas, gerando em novas formas de convivências e de conflitos que refletem tanto a falta de conhecimento quanto de tolerância ${ }^{1}$ para lidar com as diferenças raciais, étnicas e culturais.

1 Tolerância. "A. Maneira de agir de uma pessoa que suporta sem protesto uma afronta habitual contra os seus direitos, enquanto podia reprimi-la; maneira de agir de uma autoridade que aceita abertamente, em virtude de uma espécie de costume, esta ou aquela derrogação das leis ou regulamentos que está encarregada de fazer aplicar, "Os atos... de simples tolerância não podem fundamentar nem prescrição nem posse.” Código Civil Francês, 2232. (...) C. Disposição de espírito, ou regra de conduta, que consiste em deixar a cada um a liberdade de exprimir as suas opiniões, mesmo quando não as partilhamos. Ver particularmente JACOB, Devoirs, cap.XI: “A liberdade de pensamento e o dever da tolerância". Ed. GLOBOT define muito nitidamente a idéia moderna de tolerância ao dizer que ela consiste "não em renunciar às suas convicções ou em abster-se de as manifestar, de as defender ou de as difundir, mas em proibir-se todos os meios violentos, injuriosos ou 
Comparativamente, encontram-se na América Latina, desde sua colonização, diferentes etnias convivendo entre si que são: a dos ameríndios, a dos europeus, a dos negros e as de outras origens lá alocadas permitindo-nos pensar o fato como uma espécie de mundialização, ou seja, uma espécie de antecipação à atual globalização ${ }^{2}$. Desde aquela época, a região convive com contrastes decorrentes do encontro entre culturas e sua consequente mestiçagem ${ }^{3}$, um constante processo de atrito identitário que mescla colonização, resistência, adaptações materiais e morais. Portanto, esse fato serve para confirmar que a mestiçagem, enquanto fenômeno existe nos quatro cantos do Planeta, que chama a atenção para o fato de não existir culturas e etnias intactas, pois a história da humanidade resulta de diferentes encontros raciais, culturais, étnicos, em diferentes tempos e espaços, criando e recriando novos imaginários, traços físicos, culturais e também formas de pensamento.

Há diferentes graus de mesclas e de intensidades de contatos, mas sempre se manifesta a presença de sentimentos identitários intra e entre grupos que os torna coesos, determinados em suas tradições e reforçados, muitas vezes, por sentimentos etnocêntricos que defendem a purificação étnica ${ }^{4}$ e a xenofobia. Conflitos de natureza étnica são conhecidos desde longa data e, a título de exemplo,

dolorosos; numa palavra, em propor as suas opiniões sem procurar impô-las". Vocabulaire philos., sub V. D. Algumas vezes: respeito simpático pelas crenças de outrem, enquanto se consideram como uma contribuição para a verdade total (A propriedade deste sentido é discutida...)". (LALANDE, 1999: 1140-1).

2 Globalização. "Este é o processo pelo qual a população do mundo se torna cada vez mais unida em uma única sociedade. A palavra só entrou em uso geral nos anos 80 . As mudanças a que ela se refere têm alta carga política e o conceito é controvertido, pois indica que a criação de uma sociedade mundial já não é o projeto de um estado-nação hegemônico, e sim o resultado não-direcionado da interação social em escala global. Desse modo, ela enquadra na mesma discussão os temas SOCIEDADE PÓS-INDUSTRIAL e do DESENVOLVIMENTO E SUBDESENVOLVIMENTO. A palavra firmou-se em campos tão diversos quanto a economia, a geografia, o marketing e a sociologia, o que indica que seu uso é mais que uma questão de moda passageira." (OUTHWAITE, 1999: 340).

3 Mestiçagem. Conceito que pretende estender-se além da ideia de miscigenação entre pessoas de raças diferentes, pois se acrescenta a ela a mistura de culturas, fenômeno que acontece em todo o mundo.

4 Étnico, etnia ou grupo étnico. Grupos étnicos são "esses grupos que alimentam uma crença subjetiva em uma comunidade de origem fundada nas semelhanças de aparência externa ou da migração, de modo que esta crença torna-se importante para a propagação da comunalização, pouco importando que uma comunidade de sangue exista ou não objetivamente.” (WEBER apud POUTIGNAT; STREIFF-FENART, 1997: 37). 
de acordo com alguns pesquisadores, a etnicidade é um fenômeno universal presente na época moderna, precisamente por tratar-se de um produto do desenvolvimento econômico, da expansão industrial capitalista e da formação do desenvolvimento dos Estados-nações... (POUTIGNAT; STREIFF-FENART, 1997: 27).

Quando surgiu o modelo de estado nacional moderno, no Velho Mundo, implantado segundo características políticas próprias, delimitou-se artificialmente o espaço territorial estatal, promoveram-se adaptações para as diferentes comunidades de cultura, frutos de suas próprias histórias e tradições em unidade estatal nacional. Dessas mudanças obteve-se como resultado uma unificação de diferentes nações e povos, portadores de línguas, usos e costumes diferenciados, submetidos a um projeto político regido por uma Constituição, de caráter soberano, uno e indivisível.

Consequentemente, do acesso que se tem sobre o que acontece no mundo há, de um lado, os movimentos sociais de afirmação étnica, regional ou religiosa reivindicando respeito e aceitação às suas identidades originárias e apelo de reconhecimentos às diferenças frente à uniformização feita pela "economia mundo", que se pretende planetária, de produção em massa, preocupada em conquistar os mais variados tipos de mercados, impondo-lhes novos hábitos padronizados de alimentação, de programas televisivos, de moda, de filmes, de literatura, de artes em geral, que lhes permite conquistar novos consumidores e, para isso, racionaliza seus procedimentos para atingi-los. O papel da indústria cultural acaba sendo decisivo nesse caso.

Por outro lado, os movimentos de reivindicações de respeito às características identitárias nem sempre rejeitam as novidades da ordem mundial neoliberal em sua totalidade porque fazem parte de um mesmo momento da história mundial onde estão ocorrendo, simultaneamente, redefinições que envolvem situações de existência de comunidades indígenas, convivendo com uma matriz universal de uniformização do mundo; pretensões econômicas de transformar a realidade mundial em um grande mercado; a ambientação de diferentes imaginários tradicionais à lógica do mercado financeiro e à eletrônica, enfim, convivem-se num imenso "quebra-cabeças" que se constrói e reconstrói constantemente promovendo as mais variadas formas de mestiçagem. Nessas mesti- 
çagens estariam envolvidos tanto os "subúrbios" quanto os "centros" sobrevivendo conjuntamente.

Tudo isso ajuda a reforçar a ideia de que o momento atual representa uma confirmação simétrica de outros momentos da história onde foram percebidas misturas de culturas que, por uma espécie de alquimia, foram compostas de acordo com as condições e circunstâncias sociais específicas de cada momento dado, resultando em diferentes modalidades culturais e diferentes ritmos. Assim sendo, as produções morais, econômicas, políticas e religiosas sofrem diversos tipos de influências que contrastam progresso e tradição, moderno e arcaico, por tratar-se de dilemas decorrentes de um pertencimento duplo, de difícil dissociação que resulta em uma espécie de pensamento mestiço ${ }^{5}$. Um exemplo brasileiro de pensamento mestiço foi expresso por Mario de Andrade em sua obra Macunaíma. Nesse escrito, identifica-se a coexistência de valores nativos brasileiros, negros e europeus que são complexamente inseparáveis porque compõem duas faces da mesma moeda. O pensamento mestiço, captado pelo poeta, sintetiza uma situação que aproxima mundos culturais em associação e oposição constantes e que é vivido pelo personagem Macunaíma que, como anti-herói, pertence a uma realidade polimorfa, em mutação, onde ocorre ora a superposição de umas sobre as demais e ora a fusão entre elas. Em sua obra, Mário de Andrade inova quando ressalta que nessa aparente incoerência existe um sentido latente que é o da própria metamorfose e da precariedade que, juntas, alojam a verdadeira continuidade das coisas e dos fatos.

Gruzinski (1999) chama a atenção para as lacunas da pesquisa social que, a seu ver, têm uma tendência a esquecer a história de certas partes do globo e a negligenciar responsabilidades sobre os fatos. Para ele, há uma recusa em ver as mestiçagens e o seu desenvolvimento como algo irrefutável e não apenas como uma espécie de "contaminação" ou "parasitagem" étnico-cultural. Para o autor é importante valorizar o atual momento da história repleto de revisões, dentre as quais, a necessidade de recuperação e de reciclagem de certos costu-

5 Pensamento Mestiço. "conceito desenvolvido por Serge Gruzinski (1999), que ao analisar o processo da mestiçagem cultural, decorrente da Colonização, chega 'a conclusão que devido à miscigenação de valores étnicos é possível pensar numa espécie de pensamento mestiço. 
mes classificados por exóticos, inventando novos olhares que objetivem romper com os estereótipos do exotismo para estudá-lo e compreende-lo isoladamente ou através das mestiçagens percebidas tanto nas criações estéticas quanto nas ciências sociais.

No campo das criações estéticas, pode-se dizer que as funções da arte nas sociedades autóctones visam utilizar-se de valores tradicionais com o intuito de satisfazer às necessidades sociais no momento da sua criação. A arte desempenha função social determinada. E comparativamente,

enquanto o artista moderno cria conscientemente ou inventa um estilo pessoal em desafio à convenção, o artista primitivo está (...) fazendo obra de arte dentro de um estilo altamente formalizado, intensamente local, e, de há muito estabelecido (...) provavelmente, ele está de todo inconsciente das qualidades do estilo que segue; ele o utiliza como a sua língua, corretamente e sem inibição (HOEBEL; FROST, 1976, p.409).

Além da questão dos estilos, Maëva Riebel (2014) afirma que a arte desempenha um papel preponderante na edificação dos mitos de uma cultura. A imagem iconográfica representa o real através de uma potente carga simbólica. A dimensão significante que adquire o objeto reproduzido se transforma em mito, entendido na sua estreita concepção, um signo que cristaliza as crenças e as práticas sociais. Se tomarmos por sujeito a dimensão mais íntima dos contatos que se estabeleceram a partir de 1492 entre a Europa, a América e a África - a união de seres de origens diversas - suas obras de arte permitem um papel aos que durante muito tempo restaram à margem do novo sistema de representação: os mestiços. Tais obras significam a passagem de uma existência fechada, muda, a um estado oral, visual e aberto. A título de exemplos, há criações transformadas em emblemas da América Latina como o tango argentino, patrimônio imaterial da humanidade; a cuenca, dança típica dos Andes chilenos; o samba brasileiro; todos fazendo parte dos ícones nacionais e, portanto, das suas identidades mestiças.

Ainda exemplificando a mestiçagem cultural latino-americana pode-se dizer que ela é notadamente presente nos domínios religiosos onde o cristianismo é amplamente majoritário e onde as religiões autóctones se apresentam muitas vezes tingidas pelo sincretismo. A imagem 
da virgem de Guadalupe no México é um dos símbolos mais representativos dessas variâncias locais do catolicismo porque ela constitui a continuação cristianizada da deusa da fecundidade na região Azteca e fato objetivo de peregrinação que atrai milhares de fiéis a cada ano. A imagem de Guadalupe está envolta em mistérios que desafiam a ciência há cinco séculos, pois data de 12 de dezembro de 1531, apresentando detalhes como:

- o cabelo solto da Virgem de Guadalupe é um símbolo asteca da virgindade;

- uma das mãos é mais morena e a outra mais branca, indicando a união entre os povos;

- as 46 estrelas impressas no manto representam exatamente as constelações vistas do céu na noite de 12 de dezembro de 1531 ;

- os raios de sol, maior divindade venerada pela cultura asteca, se intensificam justamente no ventre da imagem de Maria, que está grávida; - a lua sob os pés, além de evocar a "mulher vestida de sol com a lua aos seus pés", descrita no Apocalipse, também evoca o próprio nome do México na língua asteca: "centro da lua";

- O anjo, representado com asas de pássaros típicos da região da Cidade do México, simboliza a junção entre a terra e o céu (ALETEIA, 2017).

Desse modo, religião e arte servem para adaptar o homem a seu universo, dando-lhe maior segurança perante forças mais poderosas do que ele próprio. Tornam-se meios de expressão de suas crenças religiosas definidora dos poderes no universo, seu alcance, sua intensidade e o modo de influir na vida cotidiana. $\mathrm{O}$ resultado do encontro de diferentes culturas, a asteca e a europeia, resultou no surgimento de um novo gênero iconográfico onde há a representação da mãe de Cristo descrita com uma série de elementos fundamentais para a vida material e espiritual local.

A religião e a arte têm forte afinidade. Tornam-se inseparáveis na medida em que a subjetividade da religião necessita ser objetivada, materializada e é nesse contexto que a arte se transforma num meio eficiente para que isso ocorra. Em outras palavras, "pela beleza artística, os objetos da religião e da magia podem ser tirados do ambiente dos artefatos ordinários ou das atividades comuns para se tornarem dotados das qualidades do extraordinário que deverão estar associados com o 
sobrenatural - com o sagrado" (HOEBEL; FROST, 1976: P.413). Além do mais, para a elaboração da arte religiosa é importante que ela consiga se aproximar do conceito subjetivo da fé e sua representação espiritual como forma de comunicação com o observador.

Acrescentando uma visão teológica, Paul Tillich, teólogo-filósofo reformado, quando visitou o Museu de Arte Kaiser-Friedrich, em Berlim, deparou-se com uma das madonas de Botticelli e sentiu que naquele momento,

para o qual não conheço outro nome a não ser inspiração, abriu-se para mim o sentido que uma pintura pode revelar. Ela pode dar acesso a uma nova dimensão do ser, mas somente quando, ao mesmo tempo, possui a força de abrir a camada correspondente da alma (TILLICH, 1961 apud DREBES, p.179).

Segundo Tillich, teria sido a partir dessa visita que ele passou a buscar a relação entre o incondicional (revelação/inspiração) do momento da criação da obra de arte e o condicionado (a materialização dessa criação). Portanto, o incondicional seria o que dá profundidade e transcendência às coisas e fenômenos da realidade e da cultura. A cultura e a religião assim se encontram num universo simbólico e o lado humano define a relação com o objeto especifico que é a obra de arte.

Entende-se, portanto que a obra de arte se compõe em relação a si mesma e à sua transcendência. O transcendental que é o que se opõe ao empírico é "uma condição à priori e não um dado da experiência [...] que tem como objeto as formas, princípios ou ideias à priori na relação necessária com a experiência" (LALANDE, 1999: p.1150). Em outras palavras, a obra de arte se eleva para além de um nível ou limite dado pelo comportamento natural, mas supõe a intervenção de um princípio exterior e superior a esta que, no caso da obra de arte sacra, se inspirará na relação do artista com um poder superior a ele. Esse poder se concebe de forma difusa, múltipla, única de Deus.

Portanto, a possibilidade de comunicação entre diferentes culturas, sua miscigenação, sua constante transformação não depende tanto das particularidades que cada qual tem, construída ao longo de sua própria história, mas principalmente devido aos elementos universais que acompanham o ser humano durante o percurso de sua existência. Esses 
"universais" seriam os responsáveis pelas formações e transformações culturais em constantes mestiçagens como pôde ser exemplificado na arte e na prática religiosa. Graças a esses elementos é que a cultura humana não cessa de ser recriada num processo de encontro entre as particularidades culturais que resultam em novas formas misturadas e enriquecidas de expressar a arte e a religião mestiças na América Latina e no mundo.

Encerrando o artigo e não o assunto aqui tratado, discutir a mestiçagem é relevante, pois apresenta uma ligação razoável com a questão da história humana, dos seus múltiplos fenômenos, momentos e situações que, conjunturalmente, tem se adicionado a uma trajetória comum e estrutural, fundante dos acontecimentos na vida da humanidade até o presente. Pensar a mestiçagem como um fenômeno perene é, de alguma maneira, tentar minimizar os conflitos decorrentes das mais diferentes ordens como os relacionados à língua, à tecnologia, à mitologia, ao sistema social, à propriedade, ao governo, à guerra, à arte e à prática religiosa como sendo temporais. Isto porque, ao inventariar todas as conjunturas históricas registradas em épocas remotas tem-se por consequência o atual momento que estamos vivendo em pleno Século XXI, ou seja, enquanto existir seres humanos vivendo nas mais diferentes partes do Planeta, a mestiçagem estará acontecendo e relativizando cada situação frente à capacidade de adaptação, criação e recriação humana para o devir.

\section{REFERÊNCIAS BIBLIOGRÁFICAS}

GRUZINSKI, Serge. La pensée métisse. Paris. Fayard. 1999.

HERSKOVITS, Melville J. Antropologia Cultural. 4 ed. São Paulo: Editora Mestre Jou, 1973. Tomo II.

HOEBEL, E. Adamson; FROST, Everett. Antropologia Cultural e Social. 2 ed. São Paulo. Cultrix. 1976.

LALANDE, André. Vocabulário técnico e crítico da filosofia. São Paulo. Martins Fontes. 1999.

OUTHWAITE, W. et al. Dicionário do pensamento social do século XX. Rio de Janeiro. Jorge Zahar Editor. 1999. 
TILLICH PAUL (1961) apud DREBES, Haidi. A teologia da arte. In: Fronteiras e Interfaces: o pensamento de Paul Tillich. Tillich em Perspectiva Interdisciplinar. São Leopoldo.

WEBER, Max apud POUTIGNAT, P.; STREIFF-FENART, J. Teorias da etnicidade. São Paulo. UNESP. 1997.

\section{REFERÊNCIAS ELETRÔNICAS}

ALETEIA BRASIL. Três fatos científicamente inexplicáveis sobre a imagem de Guadalupe. Disponível em: http://pt.aleteia.org/2016/12/12/3. Acesso em: 14.07.2017.

RIEBEL, Maëva. La peinture des castes. In: Cahiers d'etudes romaines. N.29. 2014. (pp.149-159). Disponível em: www.etudesromaines.revue. org/4607\#article-4607. Acesso em: 13.07.2017. 